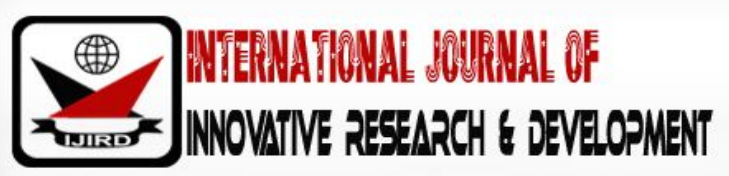

ISSN 2278 - 0211 (Online)

\section{Applying Factor Analysis to Pre-Service Teachers Re-Constructed Self-Concept/ Intrinsic Motivation Inventory}

Mohammed Nurudeen Alhassan
Tutor, Department of Mathematics \& ICT, OLA College of Education, Ghana
Jonathan A. Fletcher
Professor, School of Education and Leadership, University of Ghana, Ghana
Helena Naa Korkor Tetteh
Tutor, Department of Mathematics \& ICT, Berekum College of Education, Ghana
Samuel Aquah
Tutor, Department of Mathematics \& ICT, OLA College of Education, Ghana
Stephen Rowland Baidoo
Tutor, Department of Mathematics \& ICT, OLA College of Education, Ghana

\section{Abstract:}

The objective of the study was to find out if significant number of items and the internal consistency for each sub-scale (and the combined scale) will be enough to support the theoretical frame work of a bigger study. To do this a survey was conducted among pre-service teachers in university settings to ascertain whether their feedback will support the research. A multi-dimensional two-in-one instrument containing 40 Likert Scale items and administered to 96 pre-service teachers was used for this study known as the SCIMOT questionnaire. Based on the analysis conducted, it can be concluded that, the instrument had required significant number of items and that, the internal consistency for each sub-scale and the combined scale are sufficient to support the theoretical frame work of the bigger study. It is recommended that its continuous use is relevant across context and cultures irrespective of time.

Keywords: Internal consistency, factor analysis, multi-dimensional, sampling adequacy, identity matrix

\section{Introduction}

Educational Psychologists have developed interest in relationships between psychological variables and academic achievement. This explicit interest has resulted in establishing linkages between important psychological variables such as attitudinal, attributions, expectancies, self-perceptions, motivational orientations are affect variables identified to have a link academic achievement, by courtesy of research designs in a variety of educational contexts. Several important theories have been formulated from investigations of these linkages and relationships. These theories include Attribution Theory (Weiner, 1986), Expectancy Value Theory (Eccles, 1983), Self-Efficacy Theory (Bandura, 1997), Self-Concept Theory (Marsh, 1993), and Goal Theory (Ames, 1992). As these theories are formulated aspects of each have been researched into, including their explanatory ability with respect to academic achievement (Schunk, 1981; Bandura, 1986; and Zimmerman, 1989).

Notwithstanding these important advances, it appears no single theory within educational psychology provides a sufficient and better account of the variance in academic achievement than other theories. This situation makes Academic achievement difficult to explain, and even more strenuous to predict, no matter one's position among the theories (Dowson, Barker \& McInerney, 2004). This situation has given rise to a substantial scope for the refinement of theoretical approaches to academic achievement from a psychological perspective given way to re-constructed possibilities in three-fold: to continue to digest and fine-tune existing theories; to propose and explore new theories; and to explore potential combinations of old and new theories (Dowson, Barker \& McInerney, 2004). In this study, the third option is explored known as cross-theories in research.

Cross-theoretical studies in educational psychology are becoming increasingly vey common, and there appears to be some evidence from these studies that cross-theoretical approaches may provide additional insight explanations to academic achievement (Schell, Bruning \& Colvin, as cited in Dowson, Barker \& McInerney, 2004). For the purpose of this research a 
combination of the variables (self-concept and intrinsic motivation) were adopted and combined into a single instrument to explore their total effect on mathematics achievement.

A conceptual framework of the relationship between self-concept and intrinsic motivation on mathematics achievement (Figure 1) was proposed and used to examine the data in the study. This was designed to test whether a significant number of items as well as a sufficient and necessary internal consistency for each sub-scale and the combine instrument will support the theoretical frame work the large research.

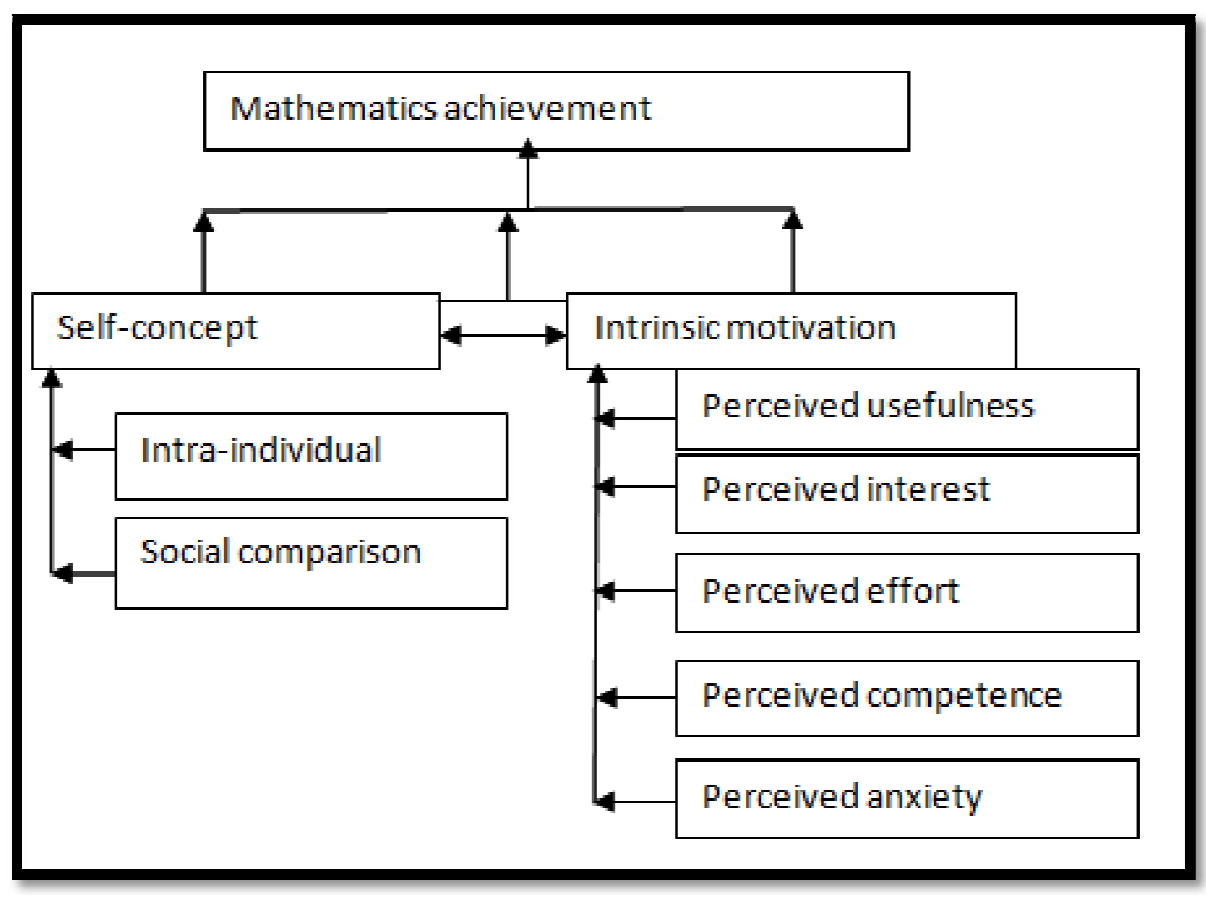

Figure 1: A Conceptual Framework for the Large Research

The top of the model is mathematics achievement with two main proposed branches, namely self-concept and intrinsic motivation. The first sub-category: Self-concept was further divided into two sub-categories, which consisted of intraindividual comparison and social comparison. The second sub-category: Intrinsic motivation was theoretically anticipated to have five sub-categories stated as perceived usefulness, interest, competence, effort and anxiety. It can be seen in (Figure 1) that, it a broad base and narrowed upwards to determine the relationships and to the extent to which mathematics achievement can be predicted from students' self-concept and intrinsic motivation.

\section{Material and methods}

A survey was conducted among pre-service teachers in university settings to ascertain whether their feedback will support the research. Survey questionnaires are easily developed and to be administered, but the analysis of survey responses can be more arduous and challenging. Fortunately, social scientists have developed analytical techniques and procedures to pave way for easy understanding of survey-based data. In this research a Self-concept and Intrinsic Motivation instrument (SCIMOT) was developed to further understand the results of the data generated from the pre-service teachers. During the development of a survey tool, literature suggested subject the assigning of individual survey items to construct domains. Subject matter experts were then engaged to validate the survey items into one of seven pre-determined concept domains. Construct domains are usually used to group survey questions/ statements into themes that sought to gather information related to a central concept or idea (Schumacker \& Lomax, 2010). These themes are statistically known and call these construct domains "factors" or "latent variables". To ascertain existence of these factors, a factor analysis is conducted. Since the construct were theoretically constructed, a confirmatory factor analysis was used. Confirmatory Factor Analysis seeks to confirm that the survey items assign to construct domains is supported by the variance/ covariance observed in the SCIMOT data.

The target population was all first year Bachelor of Education (Mathematics) students in the Department of Science and Mathematics Education. The sampling design used was non-probability convenience sampling. In this type of sampling, each member of the chosen population does not have the same chance of being selected as part of the sample, but because they happen to be present at the place and at the time of collecting the data. This design was chosen because it is the most common type of sampling that is employed in educational research (McMillan \& Schumacher, 2006). In all 96 students were sampled, but only 89 submitted their completed questionnaires. 
The instrument for the study was a questionnaire. A multi-dimensional two-in-one instrument was used for this study known as the SCIMOT questionnaire. The first part was a three-set statements for demographic survey that was used to described the sample sufficiently, followed by the main instrument to measure students' self-concept with two dimensions. The items were adopted from TIMSS 2003. The second part was the intrinsic-motivation construct and was measured with a modified 5 dimensions from the Intrinsic Motivation Inventory (IMI), namely perceived interest, perceived competence, perceived anxiety, perceived usefulness and perceived effort. The IMI is an established questionnaire which has been used extensively in studies on intrinsic motivation and self-regulation (e.g., Deci, Eghrari, Patrick, \& Leone, 1994; Plant \& Ryan, 1985; Ryan, 1982; Ryan, Connell, \& Plant, 1990; Ryan, Koestner, \& Deci, 1991; Ryan, Mims, \& Koestner, 1983). If the instruments were wildly used, will a combined form posse the construct so named for the Ghanaian context and setting? It is for this that this research is conducted.

Respondents were required to indicate the age; sex; professional qualification and the extent to which they agree or disagree to statements on a five-point Likert scale type instrument ranging from strongly disagree to strongly agree. For the purpose of analysis, strongly disagree was coded 1; disagree was coded 2; undecided 3; agree 4 and strongly agree 5. Negatively worded items attracted reverse coding as well as the items to measure perceived anxiety in solving mathematics problems.

\subsection{Theory/ Calculation}

The theoretical framework clarifies the important concepts in this study. A theoretical framework suggests my assumptions and beliefs about possible variables and paths to conduct the research. Sekaran (as cited in Radhakrishna, Yoder \& Ewing, 2007) mentioned that a theoretical framework is a conceptual model of how one theorizes or makes logical sense of the relationships among several factors that have been identified as important to the problem. It determines which questions and statements are to be answered by the research, and how empirical procedures are to be used as tools to answer these questions or verify the statements (De Vos, Strydom, Fouche \& Delport 2005). Radhakrishna, Yoder and Ewing further indicated that, a theoretical framework integrates key pieces of information, especially variables, in a logical manner, and to conceptualize a problem that can be tested. The two constructs that will be discussed and placed into context in this study are self-concept and intrinsic motivation.

\subsection{Construct Validity}

Construct validity is difficult to validate, as it involves determining the degree to which an instrument successfully measured a theoretical construct (De Vos, Strydom, Fouche and Delport, 2005). Factor analysis is used to assess the construct validity of the SCIMOT instrument. Some researchers have reported that factor analysis is useful for finding clusters of related variables and it is ideal for reducing a large number of variables into a more manageable form (Field, 2005a, 2005b; Ahadzie, 2007; Owusu and Badu, 2009). There are two preconditions that sample should meet before conducting factor analysis: first the appropriate sample size and whether sample data is not an identity matrix. These two preconditions should be met to guarantee the reliability of the factor analysis (Field, 2005a, 2005b). The data was subjected to the Kaiser-Meyer-Olkin (KMO) measure of sampling adequacy, which a value of .676. The KMO statistic varies between 0 and 1 with a value of 0 indicates that the sum of partial correlations is large relative to the sum of correlations, indicating diffusion of pattern of the correlations and hence factor analysis is likely to be inappropriate (Gorsuch, 1983; Field, 2005a). A value close to 1.00 indicates that patterns of correlation are relatively compact and so factor analysis should yield distinct and reliable factors (Field, 2005a). Literature however, recommends a KMO value of more than .50 if the sample size is adequate (Child, 1990; Field, 2005b). Subsequently, the KMO measure of this study was .68 suggesting that, the sample size for the factor analysis was met. The Bartlett's test of sphericity was also significant suggesting that the sample was not an identity matrix. The KMO and Bartlett's measure are used to measure sampling adequacy and non-identity matrix of the sample in the use of factor analysis (Field, 2005a, 2005b). The $\mathrm{KMO}$ and Bartlett's test of sphericity are presented in Table 1.

\begin{tabular}{|c|c|}
\hline Kaiser-Meyer-Olkin Measure of Sampling Adequacy. & .676 \\
\hline Bartlett's Test of Sphericity Approx. Chi-Square & 608.096 \\
\hline Df & 190 \\
\hline Sig. & .000 \\
\hline
\end{tabular}

Table 1: Kaiser-Meyer-Olkin and Bartlett's Test

\subsection{Factor Analysis}

Factor analysis seeks to identify fundamental variables, or factors, that explain the pattern of correlations within a set of observed variables (Suhr, 2006). This analysis is often used in data reduction to identify a small number of factors that explain most of the variance that is observed in a much larger number of manifest variables. It is used to generate hypotheses regarding causal mechanisms or to screen variables for subsequent analysis (e.g. to identify co linearity, prior to performing a linear regression analysis). The following steps were used for the factor analysis:

\subsubsection{Confirmatory Factor Analysis}


Confirmatory factor analysis (CFA) is a statistical technique used to verify the latent constructs in a set of observed variables. CFA allows the researcher to test the hypothesis that a relationship between observed variables and their underlying latent constructs exists (Suhr, 2006).

\subsubsection{Cluster Analysis}

Cluster analysis encompasses a number of different algorithms and methods for grouping objects of similar kind into respective categories. A general question facing researchers in many areas of inquiry is how to organize observed data into meaningful structures, that is, to develop taxonomies. In other words, cluster analysis is an exploratory data analysis tool which aims at sorting different objects into groups in a way that the degree of association between two objects is maximal if they belong to the same group and minimal otherwise. Given the above, cluster analysis is used to discover structures in data without providing an explanation or interpretation. In other words, cluster analysis simply discovers structures in data without explaining why they exist.

a. Main input variables: factors extracted.

b. Result: 6 clusters extracted

\subsubsection{Scree Plot}

It is a plot of the variance that is associated with each factor. A scree plot was used to illustrate the factors so identified. It can be seen that several factors were identified, but those that have eigen values of more than 1 were retained for the study (as show in figure 3).

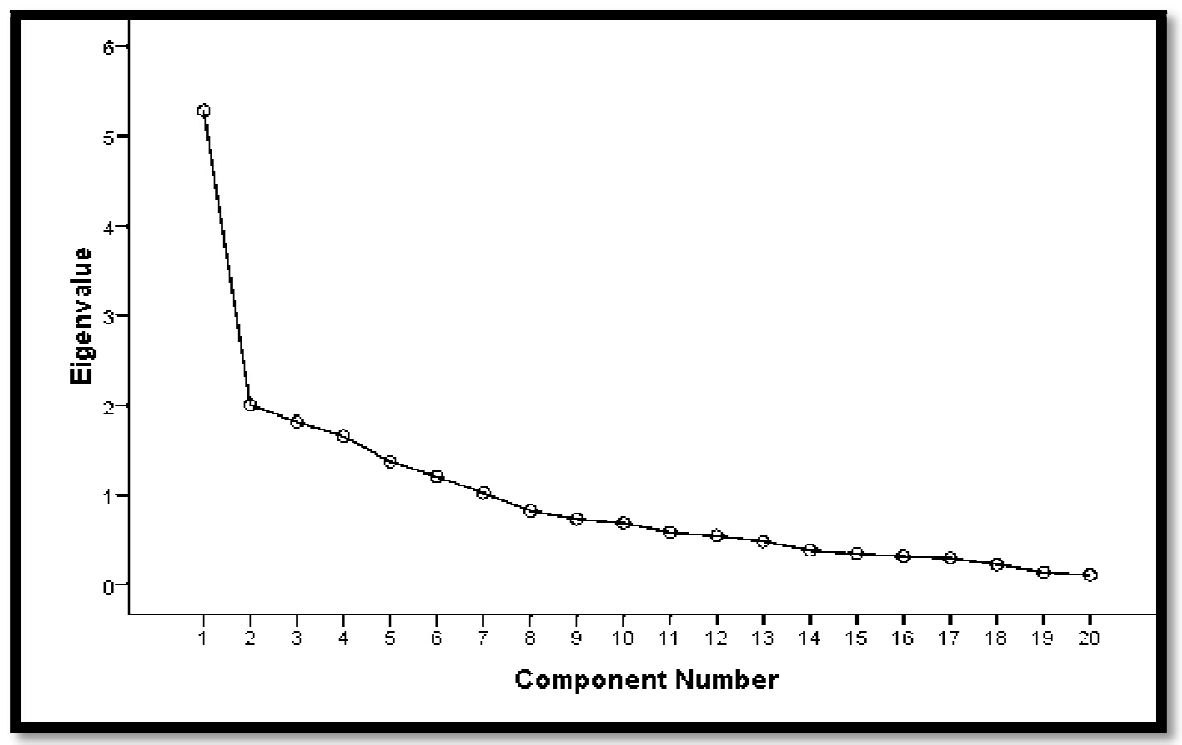

Figure 2: A Scree Plot Illustrating Factors Identified in the Study

\section{Results and Discussion}

The only hypothesis to the study was 'there is no significant number of items and the internal consistency for each scale to support the theoretical frame work of the study'. To respond to the hypothesis a Principal component analysis with varimax rotation was performed on the data. The initial factor analysis provided seven factors with eigen values greater than one and collectively accounted for $53.9 \%$ of variance. A. These components were in agreement with the 7 proposed components; however, out of the 7 components, perceived anxiety had only one significant statement loading (i.e. statement 22), as such this was deleted. In addition, two other statements (i.e. statements 15 and 17) were deleted because of their poor factor loadings (<.02). Further, 14 statements (i.e. statements 7, 8, 9, 14, 15, 16, 18, 24, 25, 26, 30, 36, 37 and 38) were deleted because they showed significant factor loadings at components they were not anticipated to measure. A second principal component factor analysis with varimax rotation was performed on the remaining 20 statements. The confirmatory factor analysis was conducted to determine if the results would indicate a better fit after the 17 statements were deleted. The factor analysis provided six factors with eigen values greater than 1 and collectively accounted for $66 \cdot 6 \%$ of variance higher than the previous. In all 20 items were used for the study and are listed under the various components.

Based on critical examination of the inherent relationships among the variables under each component, the following interpretations were deduced to represent the underlying dimensions of the components. Component 1 was labelled perceived usefulness; component 2 was labelled perceived interest; component 3 was themed intra-individual comparison; component 4 was themed perceived competence; component 5 was named social comparison; and component 6 was termed perceived effort. These names were derived based on their interrelated characteristics and combination of variables with high factor loadings. The valid $\mathrm{N}$ (Listwise) differs from the number of respondents in the analysis. This is so because one: This default method deleted respondents with missing data on one item or more items even if the missing item or items could not 
interfere on subsequent analysis; and two the variables in the correlation and regression analysis were computed, as such there are no missing values. Computed variables are transformed variables from sub-groups.

\begin{tabular}{|c|c|c|c|c|c|}
\hline & $\mathbf{N}$ & Minimum & Maximum & Mean & Std. Deviation \\
\hline $\begin{array}{c}\text { I think learning mathematics is useful } \\
\text { to me. }\end{array}$ & 86 & 1 & 5 & 4.65 & .628 \\
\hline $\begin{array}{c}\text { I believe studying mathematics is } \\
\text { important to me. }\end{array}$ & 89 & 1 & 5 & 4.65 & .709 \\
\hline $\begin{array}{c}\text { I believe learning is beneficial to me. } \\
\text { Valid N (Listwise) }\end{array}$ & 83 & 2 & 5 & 4.59 & .681 \\
\hline \multicolumn{2}{|l|}{ Table 2: Descriptive Statistics of the Perceived Usefulness Scale } \\
\hline
\end{tabular}

For component I (perceived usefulness involving 3 items), coded values ranged from 1 to 5 . A coded value of 1 or 2 on factor I indicated that the respondent believes that study of mathematics is not useful. Conversely, a coded value of 4 or 5 on factor I indicated that she or he believes that study of mathematics is useful in her or his life. A coded value 3 means the respondent is undecided on the item in question. The descriptive statistics of students' responses are illustrated in Table 2.

\begin{tabular}{|c|c|c|c|c|c|}
\hline & N & $\begin{array}{c}\text { Minimu } \\
\mathbf{m}\end{array}$ & $\begin{array}{c}\text { Maximu } \\
\mathbf{m}\end{array}$ & Mean & Std. Deviation \\
\hline I enjoy doing math. & 87 & 1 & 5 & 4.40 & .994 \\
\hline $\begin{array}{c}\text { I do not feel nervous at all when I } \\
\text { am taking exams in mathematics. }\end{array}$ & 88 & 1 & 5 & 3.65 & 1.232 \\
\hline $\begin{array}{c}\text { If I have my own way, I will stop } \\
\text { learning mathematics. }\end{array}$ & 87 & 1 & 5 & 4.49 & .987 \\
\hline I love learning mathematics. & 88 & 1 & 5 & 4.60 & .838 \\
\hline Valid N (Listwise) & 84 & & & & \\
\hline
\end{tabular}

Table 3: Descriptive Statistics of Perceived Interest Scale

Component II (Perceived interest, involving 4 items), students' responses ranged from 1 to 5 with a grand average score of 4.29. A coded value of 1 or 2 on factor I indicated that the respondent believes that study of mathematics is not interesting. Conversely, a coded value of 4 or 5 on factor II indicated that she or he believes that study of mathematics is interesting. A coded value 3 means the respondent is undecided on the item in question. The descriptive statistics are shown in Table 3. It can be seen in Table 3 that the items are generally about love, joy and interest and was not difficult to associate these items with the construct 'perceived interest'.

Scores ranged from 1 to 5 for component III (perceived competence, involving 3 items), with grand average score of 3.02. A coded value of 1 or 2 on factor I indicated that the respondent believes that she or he is not competent in the study of mathematics. Conversely, a coded value of 4 or 5 on component III indicated that she or he was competent in the study of mathematics. A coded value 3 means the respondent is undecided on the item in question. The mean, range and standard deviations of students' responses are indicated in Table 4.

\begin{tabular}{|c|c|c|c|c|c|}
\hline & $\mathbf{N}$ & Minimum & Maximum & Mean & Std. Deviation \\
\hline $\begin{array}{c}\text { I can learn mathematics } \\
\text { without difficulty. }\end{array}$ & 88 & 1 & 5 & 3.32 & 1.327 \\
\hline $\begin{array}{c}\text { I am confident that I can } \\
\text { handle my problems in } \\
\text { mathematics without } \\
\text { assistance. }\end{array}$ & 89 & 1 & 5 & 2.84 & 1.421 \\
\hline $\begin{array}{c}\text { I can handle my } \\
\text { problems in mathematics } \\
\text { without assistance. }\end{array}$ & 81 & 1 & 5 & 2.89 & 1.378 \\
\hline Valid N (Listwise) & 80 & & & & \\
\hline
\end{tabular}

Table 4: Descriptive Statistics of the Perceived Competence Scale

Table 5 shows the range, average, and standard deviation of the responses on each of the four items on component IV. For component IV (Social comparison, involving 3 items), a coded value of 1 or 2 indicated that the student believed she or he 
works hard in mathematics, but does not see the need to compare her or his score to that of their class mates. A coded value of 4 or 5 indicated that the student believed she or he need to work hard but did see the need to compare her or his score to that of their class mates in order to improve upon their scores and standing among their mates. A coded value 3 means the respondent is undecided on the item in question.

\begin{tabular}{|c|c|c|c|c|c|}
\hline Item & $\mathbf{N}$ & Minimum & Maximum & Mean & Std. Deviation \\
\hline $\begin{array}{c}\text { My friends do better than me in } \\
\text { mathematics. }\end{array}$ & 84 & 1 & 5 & 3.69 & 1.232 \\
\hline $\begin{array}{c}\text { My friends are not better than me in } \\
\text { mathematics. }\end{array}$ & 87 & 1 & 5 & 3.44 & 1.353 \\
\hline $\begin{array}{c}\text { In class, I see others to be better } \\
\text { than me in mathematics. }\end{array}$ & 88 & 1 & 5 & 2.95 & 1.500 \\
\hline Valid N (Listwise) & 84 & & & & \\
\hline
\end{tabular}

Table 5: Descriptive Statistics of the Social Comparison Scale

On Factor V (Perceived effort, involving 3 items), responses also ranged from 1 to 5 . A coded value of 4 or 5 on factor $\mathrm{V}$ indicates that students believed that they had to put in a lot of effort in order to do well in mathematics. A coded of 1 or 2 indicated that the students do not believed that they had to put in a lot of effort in order to do well in mathematics. A coded value of 3 means the respondent is undecided on the item in question. The mean, range and standard deviations of students' responses are illustrated in Table 6.

\begin{tabular}{|c|c|c|c|c|c|}
\hline & $\mathbf{N}$ & Minimum & Maximum & Mean & Std. Deviation \\
\hline $\begin{array}{c}\text { I do not try to do well in } \\
\text { mathematics. }\end{array}$ & 84 & 1 & 5 & 4.46 & .963 \\
\hline $\begin{array}{c}\text { I do not put a lot of effort in the } \\
\text { study of mathematics. }\end{array}$ & 85 & 1 & 5 & 3.98 & 1.263 \\
\hline $\begin{array}{c}\text { I do put a lot of effort in the } \\
\text { study of mathematics. }\end{array}$ & 84 & 1 & 5 & 3.82 & 1.291 \\
\hline Valid N (Listwise) & 82 & & & & \\
\hline
\end{tabular}

Table 6: Descriptive Statistics of Perceived Effort Scale

Finally, on component VI (intra-individual, involving 4 items), student responses ranged from 1 to 5 . A coded of 4 or 5 on factor VI indicated that students believed that in order to do well in mathematics it is necessary to compare one' score in mathematics with the scores in other subjects. A coded value of 1 or 2 indicated that students believed to do well in mathematics, it is not necessary to compare one' score in mathematics with the scores in other subjects. Table 7 shows the range, average, and standard deviation for the mean coded values of students' responses on each of the four items.

\begin{tabular}{|c|c|c|c|c|c|}
\hline & $\mathbf{N}$ & Minimum & Maximum & Mean & Std. Deviation \\
\hline $\begin{array}{c}\text { Learning mathematics is a lot of fun } \\
\text { to me. }\end{array}$ & 82 & 1 & 5 & 4.10 & 1.084 \\
\hline $\begin{array}{c}\text { I think I am pretty good in } \\
\text { mathematics. }\end{array}$ & 85 & 2 & 5 & 4.29 & .737 \\
\hline $\begin{array}{c}\text { I think I do pretty well in } \\
\text { mathematics. }\end{array}$ & 86 & 1 & 5 & 4.19 & .964 \\
\hline $\begin{array}{c}\text { Mathematics is not a difficult } \\
\text { subject. }\end{array}$ & 88 & 1 & 5 & 4.07 & 1.192 \\
\hline Valid N (Listwise) & 80 & & & & \\
\hline
\end{tabular}

Table 7: Descriptive Statistics of the Items on Intra-Individual Comparison Scale

In general, the average coded value for each factor were all greater than 3 indicating that students appeared to have somewhat positive views on all the items under the various construct extracted. After determining the six (6) components, two main factors were computed for the correlation and regression analysis. As earlier stated, each student response was assigned a coded value from 1 to 5 on each of the 6 components involving the 20 items. The score was determined using the 5point Likert scale from the questionnaire. "Strongly disagree" to "Strongly agree" were assigned numerical values of 1 through 5 respectively for each statement. Next, the average of all items in each of the components was calculated for each student, resulting in a mean score for each component ranging from 1 to 5 . 
With respect to the current study, the items on intra-individual comparison, social comparison, perceived interest, perceived competence, perceived usefulness and perceived effort all had high internal consistencies. Specifically, the internal reliability estimates of the six components were as follows: intra-individual comparison $=.51$ to .82 , social comparison $=.74$ to .81 , perceived interest $=.62$ to .72 , perceived competence $=.52$ to .90 , perceived usefulness $=.73$ to .85 and perceived effort $=$ .50 to .85. It is concluded from the principal and confirmatory factor analysis that the construct validity was met and as such; the research instrument was valid for the study. Base d on the confirmatory analysis, it can be concluded that the data has sufficient number of items and that, the internal consistency for each sub-scale and the combined scale support the theoretical frame work of the study. This result supports the self-concept supports Deci, Eghrari, Patrick, \& Leone, 1994; Plant \& Ryan, 1985; Ryan, 1982; Ryan, Connell, \& Plant, 1990; Ryan, Koestner, \& Deci, 1991; Ryan, Mims, \& Koestner, 1983 justified use of the instrument for the measurement of intrinsic motivation and self-regulation. The instrument was also found to be factor analytically coherent. In addition, it also agrees with McAuley, Duncan, and Tammen (1987) who have found strong support for its validity. This means the items of the combined instrument are stable across a variety of tasks, conditions, and settings, hence its reliability and validity for the Ghanaian context and settings. More so, reliability is the consistency of the measurement. It is the extent to which the results are similar over different forms of the same instrument or occasions of data collection (McMillan \& Schumacher, 2006). Any instrument that showed similarity of results of the same person or a quantity for a number of times irrespective of time and place is reliable. Strydom, Fouche, Poggenpel and Schurink (in Dambudzo 2009) declared that an instrument such as a questionnaire is said to be reliable to the extent that independent administrations of it, or a comparable instrument, consistently yields the same or similar results. Therefore, the more reproducible of the results obtained by the instrument, the more reliable the instrument

Furthermore, McMillan \& Schumacher (2006) stated that internal consistency is the most common kind of reliability, since it can be estimated from giving one form of a test only once. There are generally three types of internal consistency measures, namely the split-half-method, the Kuder-Richardson-method, and the Cronbach alpha method. This study however focused on the Cronbach alpha method.

The Cronbach alpha method assumes that all statements are equivalent in the determination of internal consistency of the questionnaire. It is a much more general form of internal consistency and is used for statements that are not scored right or wrong (McMillan and Schumacher, 2006). In this study the statements in the SC-IMOT questionnaires are not scored right or wrong. The Cronbach alpha is the most appropriate kind of reliability in the case of survey research, as well as for other questionnaires where there is a range of possible answers for each item (McMillan \& Schumacher, 2006). As was mentioned before, this study is a correlation study research design and there is a range of possible answers for each statement in the questionnaires. Therefore, the Cronbach alpha method was considered as the most appropriate measure of reliability for this study.

The internal consistency of the items from the different sub-scales for the SCIMOT questionnaire was determined with the help of the SPSS computer software program. Detailed analysis of the reliability of the instrument according to McMillan and Schumacher (2006) any instrument should have an acceptable range of reliability coefficients from .70 and .90. The overall Cronbach alpha's $\alpha$-coefficient of the SCIMOT instrument was .80. The scale reliabilities for the two constructs are as follows. The number of items and the internal consistency for each scale are: Self-concept seven items $(\alpha=.70)$; intrinsic motivation thirteen items $(\alpha=.73)$. The alpha coefficients ranged from .75 to .79 and were satisfactory on the basis of Nunnally's (1978) and McMillan and Schumacher (2006) criterion of a minimum of .70. Hence it can be said that, the instrument had the required significant number of items and that, the internal consistency for each sub-scale and the combined scale are sufficient to support the theoretical frame work of the study.

\section{Conclusion}

It can therefore be concluded that, the instrument had required significant number of items and that, the internal consistency for each sub-scale and the combined scale are sufficient to support the theoretical frame work of the bigger study. It is recommended that its continuous use is relevant across context and cultures irrespective of time.

\section{References}

i. Ahadzie, D.K. (2007). A model for predicting the performance of project managers in mass house building projects Ghana. PhD thesis, University of Wolverhampton, UK.

ii. Ames, C. (1992). Classrooms: Goals, structures and student motivation. Journal of Educational Psychology, 84, 261271.

iii. Bandura, A. (1986). Social foundations of thought and action: A social cognitive theory. Englewood Cliffs, NJ:

iv. Prentice Hall.

v. Bandura, A. (1997). Self-efficacy: The exercise of control. New York: W.H. Freeman and Company.

vi. Child, D. (1990). The Essentials of Factor Analysis, (2nd ed.). Cassel Educational Ltd, London.

vii. Dambudzo, I. I. (2009). The relationship between learner self-concept and achievement in secondary schools in

viii. Zimbabwe. Unpublished DEd-thesis. Retrieved July 2011, from http:/ / hdl.handle.net/ 10500/ 2393

ix. Deci, E. L., Eghrari, H., Patrick, B. C., \& Leone, D. R. (1994). Facilitating internalization: The self-determination theory perspective. Journal of Personality, 62, 119-142. 
x. De Vos, A.S., Strydom, H., Fouche, C. B., \& Delport, C. S. L. (2005). Research at grass roots (3rd ed.). Pretoria: Van Schaik Publishers.

xi. Dowson, M., Barker, K. L. and McInerney, D. M. (2004). Who's on first?: Causal ordering of academic self-concept, motivational goals and achievement. Proceedings of the Third International Biennial SELF Research Conference, Berlin, Germany. pp. 207-218.

xii. Eccles, J. (1983). Expectancies, values, and academic behaviours. In J. Spence (Ed), Achievement and achievement motivation. San Francisco: Freeman.

xiii. Field, A. (2005a). Discovering Statistics Using SPSS for Windows, London: Sage Publications.

xiv. Field, A. (2005b). Factor Analysis Using SPSS: Theory of SPSS: Theory and Application. Retrieved February 2011,

xv. from http:/ / www.sussex.ac.uk/ users/ andyf/ factors/ pdf

xvi. Gorsuch, R. L. (1983). Factor Analysis, Hillsdale, NJ: Lawrence Erlbaum.

xvii. Marsh, H. W. (1993). Academic self-concept: Theory measurement and research. In J. Suls (Ed.), Psychological perspectives on the self 4, (pp. 59-98). Hillsdale, NJ: Erlbaum.

xviii. McAuley, E., Duncan, T., \& Tammen, V. V. (1987). Psychometric properties of the Intrinsic Motivation Inventory in a competitive sport setting: A confirmatory factor analysis. Research Quarterly for Exercise and Sport, 60, 48-58.

xix. McMillan, J. H., \& Schumacher, S. (2006). Research in education: Evidence-based inquiry (6th ed.). Boston:

xx. Pearson.

xxi. Owusu, M. D. and Badu, E. (2009). 'Determinants of contractors' investment finance strategy in Ghana:

xxii. Conceptual and empirical explanations. Journal of Financial Management of Property and Construction, 14(1), 21-33.

xxiii. Plant, R. W., \& Ryan, R. M. (1985). Intrinsic motivation and the effects of self-consciousness, self-awareness, and egoinvolvement: An investigation of internally controlling styles. Journal of Personality, 53, 435-449.

xxiv. Radhakrishna, R. B., Yoder, E. P., \& Ewing, J. C. (2007). Strategies for linking theoretical framework and research types. Conference proceedings of the 2007 AAAE Research Conference held in Pennsylvania. Conducted by the Pennsylvania State University.

xxv. Ryan, R. M. (1982). Control and information in the intrapersonal sphere: An extension of cognitive evaluation theory. Journal of Personality and Social Psychology, 43, 450-461.

xxvi. Ryan, R. M., Connell, J. P., \& Plant, R. W. (1990). Emotions in non-directed text learning. Learning and Individual

xxvii. Differences, 2, 1-17.

xxviii. Ryan, R. M., Koestner, R., \& Deci, E. L. (1991). Ego-involved persistence: When free-choice behaviour is not intrinsically motivated. Motivation and Emotion, 15, 185-205.

xxix. Ryan, R. M., Mims, V., \& Koestner, R. (1983). Relation of reward contingency and interpersonal context to intrinsic motivation: A review and test using cognitive evaluation theory. Journal of Personality and Social Psychology, 45, 736750.

xxx. Schumacker, R. E., \& Lomax, R. G. (2010). A Beginner's Guide to Structural Equation Modeling (3rd Edition ed.).

xxxi. New York: Routledge Taylor and Francis Group, LLC.

xxxii. Suhr, D. D. (2006). Exploratory or confirmatory factor analysis? Proceedings of the Thirty-first Annual SAS

xxxiii. Conference (SUGI 31), Paper 200-3.

xxxiv. TIMSS. (2003). International Mathematics Report: Findings from IEA's Trends in international Mathematics and

xxxv. Science Study at the $4^{\text {th }}$ and $8^{\text {th }}$ Grades. Chestnut Hill. International study centre, Boston College.

xxxvi. Weiner, B. (1986). An attributional theory of motivation and emotion. New York:Springer-Verlag.

xxxvii. Zimmerman, B. J. (1989). A social cognitive view of self-regulated academic learning. Journal of Educational

xxxviii. Psychology, 81, 329-339. 